\title{
Mass Responses to Growing Elite Polarization in the U.S.: Ideological Extremism and Political Awareness
}

\author{
Jae Mook Lee
}

\begin{abstract}
In recent years scholars of American politics have paid a great attention to party elites' ideological polarization and the mass reactions to the changed political environment. Applying a novel empirical strategy, this study attempts to contribute to this body of literature examining the mass consequences of party elites' ideological polarization. More specifically, using the cumulative ANES (American National Election Study) survey (1972-2004), this paper examines how ordinary citizens have responded to the polarizing political environment in terms of changes in their ideological positions and levels of political awareness. In particular, assuming that mass effects of the polarized politics could be potentially heterogeneous in these two dimensions depending on citizens' existing positions in the distribution of dependent variables (i.e., ideological positions and political awareness), this study utilizes a quantile regression model to account for differential responses of citizen strata in addition to the ordinary regression analyses of conditional mean effect for the general electorate. Empirical findings here suggest that the general electorate not only becomes to perceive more ideological differences between the two parties, but they also tend to adopt more extreme positions on the ideological self-placement. In addition, this study demonstrates that the mass effects of growing congressional polarization are quite consistent across different strata of the electorate rather than being disproportionate. This result contrasts sharply with the claim of Fiorina et al. (2006) who argue that mass polarization is largely limited to the small subset of population with stronger ideological orientation.
\end{abstract}

Key Words: polarization, quantile regression, political awareness, ANES, electorate

ne of the most important issues in the mass polarization debate is whether the effects of growing elite polarization are confined to a small minority of the population or have extended to ordinary citizen groups or the general elec-

\footnotetext{
*Jae Mook Lee (jaemook@hufs.ac.kr) is an assistant professor in the Department of Political Science and International Studies at Hankuk University of Foreign Studies in Seoul, South Korea. He holds a Ph.D. in political science from the University of Iowa. His research interests include political behavior, public opinion, and research methods in American politics and comparative politics. He has published his work in peer-reviewed journals such as Journal of International and Area Studies, PS: Political Science and Politics, and Social Indicators Research.
}

This work was supported by Hankuk University of Foreign Studies Research Fund.

The Korean J ournal of International Studies Vol.13-3 (December 2015), 609-634. http://dx.doi.org/10.14731/kjis.2015.12.13.3.609

(c) 2015 The Korean Association of International Studies 
torate (Abramowitz and Saunders 2008; Fiorina et al. 2006, 2008). Using the cumulative American National Election Study (ANES) survey data from 1972 to 2004, this paper examines how ordinary citizens have responded to the polarizing political environment in terms of changes in their ideological positions and levels of political awareness. In particular, assuming that the mass effects of polarized politics could be potentially heterogeneous in these two dimensions depending on citizens' existing positions in the distribution of dependent variables (i.e., ideological positions and political awareness), this study utilizes a quantile regression model to account for differential responses of citizen strata in addition to the ordinary regression analyses of the conditional mean effect for the general electorate.

Just as scholars have argued about whether mass publics have responded to growing elite polarization by increasingly taking more ideologically extreme positions, scholarly attention also has been given to other dimensions of mass reactions to ideological divisions in the U.S. Congress (Ellis and Ura 2008; Hetherington 2008; Levendusky 2010; Rogowski 2012). Indeed, from the electorate's side, as the political environment changes with growing partisan polarization among elites,citizens would not only be more likely to adopt ideologically polarized attitudes, but their political behavior, in terms of how they perceive or how they interact with politics, will likely change accordingly. ${ }^{1}$ Among several potential mass consequences, I focus here on the informational aspects of increasing ideological polarization among politicians. The disappearance of ideologically moderate members as a result of ongoing congressional polarization implies that the issue positions of politicians have become more clarified compared to less polarized eras. If this is the case, more citizens are expected to perceive distinctions betweenthe ideological preferences of parties or candidates with less difficulty. Thus, growing elite polarization could enhance levels of mass political awareness by reducing positional ambiguity in the policy issue preferences of elected officials (Claassen and Highton 2009).

Adopting the definition of Zaller (1992, 21), I conceptualize political awareness as "the extent to which an individual pays attention to politics and understands what he or she has encountered...Political awareness denotes intellectual or cognitive engagement with public affairs as against emotional or affective engagement or no engagement at all.” As Zallerexplains, similar concepts to political awareness in the discipline include political expertise, cognitive complexity, political involvement, attentiveness, sophistication, and political acuity. I pay atten-

\footnotetext{
${ }^{1}$ In this article, elites mainly refer to elected officials such as congressmen.
} 
tion to changing levels of political awareness in transformed political environments, not only because the increased sophistication of voters could enhance the quality of democratic decision making, but also because greater amounts of available political information is linked to increased political engagement of the public (Matsusaka 1995; Riker and Ordeshook 1968; Larcinese 2007; Lassen 2005). Indeed, if growing elite polarization would improve levels of civic political awareness and facilitate political engagement of the public following the virtuous circle proposed above, these consequences might be described as 'beneficial' aspects of political polarization (Levendusky 2010).

Empirical findings here suggest that the general electorate not only comes to perceive more ideological differences between the two parties, but citizens also tend to adopt more extreme positions of ideological self-placement. In addition, the mass effects of growing congressional polarization are consistent with the polarization of the electorate rather than being disproportionate across the different ideological positions of citizens. This result contrasts sharply with the claim of Fiorina et al. (2006), who argue that mass polarization is largely limited to a small subset of the population with a stronger ideological orientation. When it comes to mass political awareness, growing ideological divergence between the parties tends to enhance the public's political awareness in aggregate. Further, evidence indicates that a significant relationship is consistent across all levels of political awareness instead of disproportionately advantaging the most aware citizen groups. This finding contrasts with the finding of Claassen and Highton (2009) who demonstrate that only the well-informed strata of the population are advantaged in terms of political awareness from growing elite polarization.

Using the cumulative ANES survey from 1972 to 2004, I start to explore how far citizens shifted to ideologically extreme positions in response to growing elite polarization.This paper then examines whether the growing ideological divergence between the two parties significantly increased levels of political awareness among the public. Together with conventional regression analyses (e.g., conditional mean effect), I employ a quantile regression strategy to explore whether different strata of the population are affected unequally by agrowing ideological divergence among elites.

\section{MASSREACTIONS TO THE GROWING IDEOLOGICAL POLARIZATION OF ELITES: IDEOLOGICAL EXTREMISM AND POLITICAL AWARENESS}

Scholarly works on polarization have paid separate attention to elite and mass 
polarization. While a recognized consensus exists regarding a growing polarization in the U.S. Congress, less agreement exists about polarization of mass attitudes (Abramowitz and Saunders 2008; Baldassarri and Gelman 2008; Fiorina and Abrams 2008; Hetherington 2009). Scholars have debated the presence of mass polarization, and the primary puzzle from competing evidence is how can the electorate not be ideologically polarized when political elites who are electorally linked to their constituents are more divided than before? If the political elite class is ideologically more divergent, while the electorate is much less polarized, this state of mismatch obscures our existing knowledge about representative democracy because the widening disconnect in terms of ideological distribution can be seen as "the breakdown of representation in American politics," as Fiorina and Abrams (2009) have subtitled their book.

According to the argument of Fiorina and his colleagues, mass attitudes have altered in response to elite polarization but ordinary citizens are not more polarized than before because ideological moderates or centrists have not substantially been diminished (Fiorina et al. 2006; Fiorina and Levendusky 2006; Levendusky 2009). Fiorina et al. (2008) argue that only a small segment of the population with strong ideological orientations, such as political elites and activists, have become polarized, while a majority of ordinary citizens remain moderate. Instead of increasing ideological polarization among the general electorate,party sorting has occurred at the mass level, the authors contend. As elites are increasingly polarized, the ideological positions of political parties have become more clarified, and voters have more easily aligned their ideologies with party affiliations using these clearer elite cues. Scholars are divided, however, as to whether party sorting is just another aspect of popular polarization. ${ }^{2}$ For example, Abramowitz (2006) and Jacobson (2006) contend that Fiorina and Levenduskydownplay their own evidence of partisan polarization in the electorate by referring to it as sorting, although both concepts are closely related.

Sorting is a top-down process because the growing partisan division among political elites increases correlation between individual ideology and the party affiliation of the masses. The rise and growth of partisanship among politicians has reduced ideological ambiguity between the parties, and the concomitant greater polarization in Congress enables ordinary citizens to distinguish more

\footnotetext{
${ }^{2}$ To avoid any confusion in concepts used here, partisan polarization is understood as the party sorting that basically indicates increased correlation between individual partisanship and ideology, while popular or masspolarization represents ideological polarization or radicalization of mass public opinion. Actually, party sorting and opinion radicalization are the first and second kinds of polarization discussed in Gelman's (2008) explanation.
} 
clearly between the policy positions of different parties. Thus, growing elite polarization could potentially improve the informational environment in which political processes operate.

Since Converse's (1964) seminal work, scholars have long been skeptical as to whether ordinary citizens hold consistent belief systems across issue dimensions. If the mass public relies significantly on elite cues to understand the complex nature of ideology and politics, the ideological polarization of elites should enhance consistency in mass attitudes because cue-taking becomes much easier for a broad range of people (Levendusky 2010). Levendusky finds that elite polarization allows ordinary citizens to adopt more consistent attitudes in terms of cross-policy preferences. Actually, this finding corresponds, to some degree, to the conceptual meaning of partisan sorting because, in essence, it implies that more people become capable of correctly linking parties to their preferred ideological positions. In accordance with this optimistic view, Abramowitz and Saunders (2008) report a substantial increase in the proportion of the electorate who are more politically aware in the 2000s compared to the 1950 s and 1960 s. They suggest that about 75 percent of American voters were able to perceive important differences between the parties and about 85 percent were concerned with who won the presidential race during the 2000 s, whereas only about 50 percent of voters felt important differences between the parties and only 65 percent cared about the presidential election outcome during the 1950s and 1960s. Similarly, Brooks and Geer $(2008,35)$ describe potential informational benefits of elite polarization as follows:

\footnotetext{
"The most obvious benefit of polarization is to offer a sharper distinction between the two political parties. For partisans, the benefit of this sharper distinction is clear: elite polarization gives partisans further reinforcement for their preexisting ideological and policy preferences. For moderates, the choices are made clear enough that one option is more likely to be preferred, at least marginally, over the alternative. For those who have lower levels of overall political knowledge, it should make the lines of differentiation on at least the most salient issues clearer than they would be otherwise."
}

Despite these optimistic expectations, it is not obvious yet whether polarized politics in Congress has enhanced the overall informational environment or has just disproportionately affected a few segments of the population with a certain level of cognitive ability. Some scholars have paid more specific attention to the unequal influences of growing partisan polarization on mass awareness of poli- 
tics based on social stratification. For example, Hetherington (2001), who showed that partisanship has resurged in the electorate in accordance with greater congressional polarization, indicates that the strongest effect of elite polarization on mass partisanship is found among citizens with more political knowledge (measured by levels of formal education). ${ }^{3}$ Focusing on the informational role of polarization, Claassen and Highton (2009) find that only wellinformed citizen groups became more partisan in their views in response to growing elite polarization. 4 They thus argue that the clarification associated with the increasing policy divergence of political elites does not close the gaps between citizen groups. Ellis and Ura (2008) also confirm that the strength of partisan thinking varies by levels of income and the formal education of citizens. They show that mass partisan salience on economic issues is most prominent among citizens with higher education and those with low incomes, whereas stronger mass partisanship in terms of cultural issues is found among citizens with less education and higher incomes. When it comes to the issue of consistency, Baldassari andGelman (2008) report that ideological constraints on the general public is still extremely low even with the increased level of partisan sorting, and coherent attitudes are still confined to a small segment of the population with certain levels of wealth, partisanship, and political sophistication. To summarize, all this existing evidence indicates that elite polarization will have heterogeneous effects on mass political awareness in accordance with the level of citizen political expertise.

Therefore, in essence, the remaining questions are:1) whether most ordinary voters still remain ideologically moderate or relatedly centrists, and whether increasing ideological extremism is largely confined to more active and politically aware subsets of the population (Fiorina et al. 2006) despite growing elite polarization; or 2) whether reduced ideological ambiguity disproportionately enhances the levels of political awareness of individuals (Claassen and Highton 2009). In the following sections, by empirically modeling the nature of elite influence on the electorate, I investigate whether population strata that are different according to their existing level of political awareness have reacted differently to the changing political environment in terms of their ideological preferences and level of political awareness.

\footnotetext{
${ }^{3}$ Similar to the approach adopted here, Hetherington (2001) uses a contextual variable to measure the level of elite polarization in each congressional session included in his analysis. He constructs the measure by calculating the mean Euclidean distance in the DW-NOMINATE scores between Democrats and Republicans in the House and then merges this with individual-level survey data by year.

${ }^{4}$ In the subsequent analysis, I provide a more detailed examination of how individuals respond disproportionately to growing elite polarization in terms of their level of political awareness.
} 


\section{EMPIRICALLY MODELING THE DISPROPORTIONATE EFFECTS ON THE MASS PUBLIC USING THE QUANTILE REGRESSION ANALYSIS}

Has the number of ideological extremists increased among the mass public? While testing this hypothesis about mass polarization, I also examine the disproportionate effects of elite polarization on different quantiles of individual ideological positions. 5 Following this question,I investigate the effects of elite polarization on mass political awareness to see if it indeed enhances levels of political attentiveness among citizens. Finally,I test whether the most informed citizen groups disproportionately benefit in terms of political awareness or if the informational effects that result from increased policy divergence between the two parties occur in the general electorate as a whole.

In order to test these hypotheses, I apply quantile regression models to estimate potentially differential effects of elite polarization on various quantiles in the conditional distribution of citizens (Hao and Naiman 2007; Koenker and Hallock 2001). While conventional linear regression models (OLS) focus only on the conditional expectation of a dependent variable given a specific value of a covariate (i.e., $E(y \mid x)$ ), the quantile regression analysis accounts for the full conditional distributional properties of the response variable (Hao and Naiman 2007). Thus, for example, with the quantile regression model we can estimate nine different fitted regression lines if we want to separately estimate the differing effects of a covariate on each quantile (from the $.1^{\text {th }}$ to $.9^{\text {th }}$ quantiles) of a conditional distribution of a dependent variable, whereas a linear regression model produces only a single representative slope estimate. In a simple setup of quantile regression estimation, we generally specify the empirical model as $y_{i}=\beta_{0}^{q}+\beta_{1}^{q} x_{i}+\varepsilon_{i}^{q}$, where $\mathrm{q} \in(0,1)$ indicates the proportion of the population having values below the quantile at $\mathrm{q}$. The corresponding conditional quantile regression function is defined as $Q_{q}(y \mid x)$. Hence, if we are interested in comparing the effects of increased policy divergence on levels of political sophistication between the $.10^{\text {th }}$ quantiles (the least informed) and the $.90^{\text {th }}$ quantiles (the most informed) of the conditional political awareness distribution, we can compare quantile-specific regression slopes for those two quantiles $\left(\beta^{10}\right.$ and $\left.\beta^{.90}\right)$. If the estimated value of $\hat{\beta}^{.90}$ is substantially greater than $\hat{\beta}^{10}$, this would indicate that the most informed group dispropor-

\footnotetext{
${ }^{5}$ As we examine the link between elite and mass polarization, some people might argue that we are uncertain about the direction of the causal effects between the two groups. I assume the causal direction of elites to masses since we are interested here in the potentially heterogeneous mass responses to elite influence.
} 
tionately benefited from the enhanced informational environment. In general, if quantile-specific regression coefficients for the degree of the congressional polarization variable tend to increase with $p$, we can also infer that more politically aware groups tend to be more responsive to the changed political environment compared to less aware citizens.

\section{MEASURMENTS OF PRIMARY CONCEPTS AND OTHER CONTROLS}

While the previous section specifies the empirical strategy of this research, the next section describes how I measure the primary concepts discussed above using the American National Election Study (ANES) cumulative data from 1972 to $2004 .{ }^{6}$

\section{POLITICAL AWARENESS}

One of the primary dependent variables in this study is ascale of political awareness constructed using 19 survey items that have been adopted by previous researchers to measure levels of political awareness, sophistication, and knowledge (Claassen and Highton 2009; DelliCarpini and Keeter 1993; Dow 2009; Hetherington 2001; Holbrook 2002; Zaller 1992). I chose 19 ANES questions that have been consistently asked across different iterations of the survey, which means that the measures only include items that appear in every presidentialyear survey from 1972 to $2004 .{ }^{7}$ By its construction, the political awareness variable measures levels of neutral factual knowledge, ability to correctly place certain political objects, such as parties and presidential candidates, on issues and ideological dimensions, willingness to rate those political objects on feeling thermometers, and degrees of partisan thinking. To illustrate, the ANES asks respondents some factual knowledge, and the respondent receives 1 if the respondent provided a correct answer and $\mathrm{o}$ if the answer is wrong (or the respondent doesn't know). Using questions asking respondents to locate the parties' (or the candi-

\footnotetext{
${ }^{6}$ Since some of central indicators have not been incorporated yet into the 2008 ANES survey, this study only covers from 1972 to 2004.

7 One factual question is not available in the 2004 survey. The item is: "knows incumbent status of a House candidate" (VCFo978). Except for this factual knowledge question, all the other 18 indicators are included in every presidential survey from 1972 to 2004. Despite the unavailability of the item (VCFo978) in 2004, I decided to keep the question because factual political knowledge is "the best available measure of political awareness" (Zaller 1992, 336).
} 
dates') ideological positions, I assigned a score of 2 if the respondent places Democrats to the left of Republicans, assigned a score of 1 if the respondent places the two political parties in the same position, or assigned a score of $o$ if the respondent locates Republicans to the left of Democrats. For feeling thermometers, I assigned a score of 2 if the respondent gave a non-50 rating, assigned a score of 1 if the respondent gave a rating of 50, and assigned a score of $\mathrm{o}$ if the respondent did not give a rating. The ANES includes a set of questions assessing the attitudes of respondents (likes or dislikes) toward political parties and presidential candidates, which I coded $o$ if the respondent provided no reasons to like (or dislike) the party or candidate, coded 1 if the respondent provided one reason, and coded 2 if the respondent provide two or more reasons. ${ }^{8}$ More details about the specific list of survey items and coding rules are described in the Appendix at the end of the paper. In addition to these, the interviewer rating that has been employed by other scholars (e.g., Claassen and Highton 2009; Zaller 1992) is also regarded as a valid instrument of political awareness, thus this item is also combined with the awareness scale. As described above, I recoded responses to these items to create comparable measures across different questionsthen calculated a mean to use as a measure of political awareness. Rather than applying list-wise deletion for any missing value in an observation, I compute a mean if respondents answered more than two-thirds (13 responses) of the 19 survey items. As a consequence, the number of cases increases from 4,253 (after eliminating all missing values) to 17,733 . The correlation between the measure used here and the measure adopting the list-wise deletion is high 0.9989 ( $\mathrm{p}<0.001)$.

The group of indicators used here for measuring political awareness fits the standard set used by Zaller (1992), who conducted comprehensive research on mass political awareness. Previous researchers have employed either all or some of these aforementioned indicators of political sophistication to measure political awareness or knowledge. For example, Holbrook (2002) measures political knowledge by counting the total number of candidate evaluations using only questions asking reasons why respondents like or dislike a major party candidate. Dow (2009) adds self-ideological placement to the location-test and objective knowledge questions when he measures political knowledge. For example, he assigns a value of 1 if the respondent self-places on a 7-point ideological scale, 0 otherwise. I do not include this indicator of ideological self-placement as a measure of political awareness, however, since respondents with ideological orientations may not necessarily be more politically sophisticated. Rather, this ideolog-

\footnotetext{
${ }^{8}$ For the items used in feeling thermometers, and their effects on responses to parties and presidential candidates, I follow the coding rules of Claassen and Highton (2009).
} 
ical dimension would be more related to the degree of ideological extremism that is addressed by the deviation variable introduced later. The measure used by Claassen and Highton (2009) was most similar to what is used here, with about 80 percent of items adopted here overlapping with the awareness indicators employed by the two scholars. While awareness measures include factual questions about knowing the Senate majority party and recalling the names of House candidates, they do not include the objective knowledge question asking if respondents know the incumbency status of the House candidates running in their districts. The main difference between the political awareness measures used here and those used by Claassen and Highton comes out of the approach to how to handle different combinations of indicators available in each survey year. To account for the political context in which those awareness indicators were asked and evaluated, Claassen and Highton calculated respondents' knowledge scores on a survey-by-survey basis then divided respondents into quartiles based on obtained scores. Thus, the awareness measures of Claassen and Highton (2009) incorporated some indicators that were not included in every survey. Different from their indirect approach, this project confines the number of awareness items to the ones asked in every presidential-year survey since I construct a variable measuring levels of political awareness for each respondent rather than dividing respondents into four groups in respective survey cohorts according to the respondent's level of awareness.

\section{ELITE POLARIZATION}

Elite polarization serves as the primary independent variable in the prediction models of mass public polarization. I tap into this ideological polarization among elites two different ways. First, I measure policy divergence using the (decreasing) percentage of overlapping members in the House on an ideological scale. To measure the ideological preferences of House members, I use the first dimension DW-NOMINATE that assesses members' policy positions in terms of support for government intervention in the economy or placement on a conventional liberalconservative spectrum. 9 This measures the factions of the House of Representatives whose ideological preferences overlap across the two parties during each congressional year. Given that the proportion of overlapping members tends to decrease with growing ideological divergence between the two par-

\footnotetext{
9 The DW-NOMINATE is available to use from the VOTEVIEW website, http://voteview.com/ political_polarization.asp.
} 
ties, I subtracted this overlapping percentage from the number one and used this scale as a primary indicator of partisan polarization (i.e., divergence). I prefer this divergence indicator over the mean difference (distance) scale between the two parties, which is more frequently used by other scholars as an index of elite polarization (Hetherington 2001; McCarty et al. 2006) because increased distance between the two means (Democrats and Republicans) does not necessarily indicate the absence of ideological convergence at the center. Indeed, the ideological preferences of conservative Democrats locating to the right end of the distribution for Democrats and liberal Republicans locating to the left end of the distribution for Republicans could still possibly overlap at the center of the distribution, even when a vast majority of members of the respective parties shift to more extreme positions, thus increasing the mean distance. The correlation between the mean difference and the divergence between the two parties (Democrats and Republicans) is 0.86 , while the correlation between the mean distance and the percent of moderate House members (another way of measuring congressional polarization) is -0.98 .

Since I am interested here in how elite politics affects mass political behavior, I merge this contextual variable with the individual-level data by matching congressional sessions with each presidential-survey year, similar to the work of Hetherington (2001). Hetherington (2001) lags by one congressional year as he merges the contextual data because public opinion does not immediately respond to changes in the policy positions of House members. However, I do not lag one year here because each congressional session begins more than a year before each survey. For example, I attach a computed divergence score for the 92nd Congress (1971-1972) to the each of the respondents of 1972 ANES survey.

As a second measure of the contextual change resulting from growing elite polarization, I use period-based dummies. Claassen and Highton (2009) divide the survey data into three periods (1972-1982, 1984-1992, and 1994-2004) and run separate regressions using subgroup data, since they consider each period as a proxy for political environmental change. Hussey (2011) also adopts this periodeffects-based approach and adds decade dummies (1990s and 2000s) to her regression models for political engagement. Similar to their approach, I include two period-specific dummies for 1984-1996, 1996-2004, while 1972-1984 was used as the reference period. Instead of adding decade-by-decade time effects (i.e., 1980s, 1990s, and 2000s), I chose these specific period effects because, according to a recent analysis of ongoing elite polarization (Theriault 2008), levels of polarization dramatically increased around 1984 with the disappearance of southern conservative Democrats up until after the Republican takeover of Congress in 1994. The correlations between the divergence variable and the three 
period effects (1972-84, 1984-96, and 1996-2004) are -0.961, 0.273, and 0.527, respectively. As expected, a positive correlation is high between the elite polarization contextual variable and the period-effect of 1996-2004, while a negative correlation is fairly high in the period 1972-1984.

\section{IDEOLOGICAL DEVIATION}

I employ estimated levels of the ideological deviation of each individual from a majority of fellow citizens as an individual-level measure of polarization. Assuming that a majority of citizens still remain ideologically moderate (Fiorina et al. 2006; Levendusky 2009), we might argue that the individuallevel of ideological polarization is higher when an individual is more different from the ideological preferences of a majority of citizens. I compute this ideological deviation measure as an absolute mean deviation of the ideological score measured on a 7point liberal-conservative scale. More specifically, I first calculated mean ideology scores for each survey year and then I obtained absolute-deviation of an individual score from these cohort-based means. So, if this ideological deviation score moves away from $\mathrm{o}$, it indicates that the individual holds rather an extreme ideological position in the survey cohort to which he/she belongs. As a dependent variable, this variable helps us evaluate how much the general electorate became ideologically polarized in response to a moreintense ideological division among elites. In other words, using this variable I test whether ideological polarization has extended from elites to the masses (Abramowitz and Saunders 2008; Fiorina et al. 2006, 2008).

\section{PERCEIVED IDEOLOGICAL DIFFERENCES BETWEEN THE TWO PARTIES}

Hetherington (2001, 2008) adopts perceived ideological distance as another dimension of elite polarization and argues that this variable accounts for an indirect effect of elite polarization on mass partisanship through citizen perception. In other words, perceived ideological distance functions on the right-hand side as an indirect measure of elite polarization that is reflected in the minds of voters. Yet, we need to be very cautious to incorporate the perceived difference variable into the covariance matrix of our political awareness model since this variable can be endogenous to the awareness prediction given that an individual's perception of ideological differences can reflect his or her cognitive ability. 
Hetherington (2001) also employs perceived ideological distance as the dependent variable to test the effects of elite polarization on mass perceptions of ideological clarity. He finds that mass perceptions of the ideological differences between parties increase as party elites become more polarized. Thus, I utilize this popular perception variable as a proxy for assessing the level of ideological awareness among the masses regarding growing polarization among congressional elites.

\section{OTHER CONTROL VARIABLES}

In addition to the primary covariates of interests, a number of factors identified as significant predictors of mass political behavior were added as control variables. Based on previous literature focusing on political knowledge (Barabas 2002; DelliCarpini and Keeter 1993; Dow 2009; Mondak 1999; Prior 2005; Tolbert et al. 2003), the political awareness model used here includes interest in politics, media exposure to election campaigns, political efficacy, the strength of partisanship (4-point scale), and a group of demographic background variables, including education, age, race (dummies for Black and Latino), sex (female dummy), and income (5-categories). Media exposure counts the number of "yes" answers to ANES items asking about a respondent's exposure to campaign media (TV, radio, newspaper articles, and magazines), which ranges from o to 4 . The political interest variable measures levels of interest in government and public affairs and ranges from 1 (hardly at all) to 4 (most of the time). Political efficacy is measured by combining the responses to two ANES questions asking whether "people like me don't have any say about what the government does," and "public officials don't care much about what people like me think." Barabas (2002) and Mondak (1999) also add a frequency of political discussion into the empirical specification but, since the political discussion variable is only available from 1984 onward in our data, I only include the level of political interest (4-point scale) and media exposure variables, which have fairly high correlations (0.44 and 0.37 , respectively), with the political discussion variable to preserve the number of observations. Also, given that political interest and media exposure measures are often considered as proxies for political awareness (Zaller 1992), I test separate empirical models with and without these variables to account for potential endogeneity.

Hetherington (2001) controls for the two contextual variables - off-year elections and divided government - that may also influence mass perceptions of the political ideological differences between the parties. We do not need to control 
here for off-year elections since this study only examines presidential election years from 1972 to 2004. According to Hetherington (2001), divided government could have two conflicting effects on public perceptions of the differences between the two parties. On the one hand, ideological distinctiveness can be more pronounced between the two parties during periods of a divided government. Thus, it would become easier for people to distinguish between the parties ideologically. On the other hand, divided government can present difficult choices for citizens deciding which party is responsible for the ideological direction of the country between the president from one party and a Congress largely composed of members from the other. Therefore, I control for periods characterized by divided government (dummy variable, 0 or 1 ).

\section{THE EFFECTS OF ELITE POLARIZATION ON INDIVIDUAL IDEOLOGICAL EXTREMISM}

In this section, using ideological deviation as a proxy for a degree of mass ideological polarization, I investigate whether ordinary citizens became polarized by responding to growing elite polarization. In addition, I also examine how citizens perceive elite polarization using the perceived ideological distance variable. Table 1 summarizes the outputs of the linear regressions with ideological deviation employed as a first dependent variable (models 1-3), and then perceived ideological distance employed as a second dependent variable (models 4-6). I apply two different specifications to each of the dependent variables to examine the effects of elite polarization; namely, I only include the estimated divergence variable in models (1) and (4), whereas I rely on the contextual periodeffects for 1984-1996 and 1996-2004 in models (2) and (5). Models (3) and (6) combined both contextual variables into one model. As shown in Table 1, elite polarization tapped by the two measures has significant positive effects on the ideological polarization of citizens and their perceptions of elite polarization, given that 1996-2004 is the most polarized period. As the levels of ideological divergence in the House increase, individuals are more likely to see greater ideological difference between the parties (see positive coefficients of the divergence variable in models 4 and 6), and are more likely to take ideologically extremist positions (see models 1 and 3). In addition, given that congressional members have become increasingly polarized over time since the 1970s, the period effects for 1984-1996 and 1996-2004 also indicate that elite polarization increases the likelihood of citizens shifting to more extreme ideological positions. Yet, the positive significant effects for those time dummies disappear in models (3) and (6) as we control for ideological diver- 
gence explicitly, and this might imply that increased mass ideological polarization is driven by elite polarization rather than by pure time effects. Even after controlling for the time effects, the positive effects of ideological divergence show statistical significances in full in models (3) and (6). Other than the effects of the elite polarization variables, it is noteworthy that divided government has significant negative effects on ideological deviation (model 2) and on perceived ideological distance (models 4-6). This could be happening because individuals encounter more difficulties deciding who is responsible for the ideological direction of the government between a president from one party and a Congress composed chiefly of members from the other. In sum, the findings indicate that the masses became ideologically more polarized in accordance with growing elite polarization, as revealed in both measures of individual-level polarization.

Table 1. The Effects of Elite Polarization on Mass Ideological Polarization

\begin{tabular}{|c|c|c|c|c|c|c|}
\hline \multirow{2}{*}{ Variables } & \multicolumn{3}{|c|}{ Ideological Deviation (Extremism) } & \multicolumn{3}{|c|}{ Perceived Ideological Distance } \\
\hline & (1) & (2) & (3) & (4) & (5) & (6) \\
\hline $\begin{array}{l}\text { Divergence } \\
\text { in the House }\end{array}$ & $\begin{array}{l}0.148 * * * \\
(0.028)\end{array}$ & & $\begin{array}{l}0.123 \text { * } \\
(0.049)\end{array}$ & $\begin{array}{l}0.586 \text { *** } \\
(0.058)\end{array}$ & & $\begin{array}{l}0.562 \text { *** } \\
(0.097)\end{array}$ \\
\hline Strong Partisanship & $\begin{array}{l}0.139 * * * \\
(0.007)\end{array}$ & $\begin{array}{l}0.138^{* * *} \\
(0.007)\end{array}$ & $\begin{array}{l}0.139 * * * \\
(0.007)\end{array}$ & $\begin{array}{l}0.315^{* * *} \\
(0.015)\end{array}$ & $\begin{array}{l}0.314^{* * *} \\
(0.015)\end{array}$ & $\begin{array}{l}0.315^{* * *} \\
(0.015)\end{array}$ \\
\hline Divided Government & $\begin{array}{l}-0.026 \\
(0.017)\end{array}$ & $\begin{array}{l}-0.042 \text { * } \\
(0.020)\end{array}$ & $\begin{array}{l}-0.028 \\
(0.021)\end{array}$ & $\begin{array}{l}-0.143^{* * *} \\
(0.038)\end{array}$ & $\begin{array}{l}-0.202 \text { *** } \\
(0.043)\end{array}$ & $\begin{array}{l}-0.151^{* * *} \\
(0.044)\end{array}$ \\
\hline Education & $\begin{array}{l}0.184^{* * *} \\
(0.008)\end{array}$ & $\begin{array}{l}0.185^{* * *} \\
(0.008)\end{array}$ & $\begin{array}{l}0.183^{* * *} \\
(0.008)\end{array}$ & $\begin{array}{l}0.230 * * * \\
(0.016)\end{array}$ & $\begin{array}{l}0.239 * * * \\
(0.016)\end{array}$ & $\begin{array}{l}0.230^{* * *} \\
(0.016)\end{array}$ \\
\hline Age & $\begin{array}{l}-0.001 * \\
(0.0004)\end{array}$ & $\begin{array}{l}-0.001 \dagger \\
(0.0004)\end{array}$ & $\begin{array}{l}-0.001 * \\
(0.0004)\end{array}$ & $\begin{array}{l}0.002 \text { * } \\
(0.001)\end{array}$ & $\begin{array}{l}0.002 * \\
(0.001)\end{array}$ & $\begin{array}{l}0.002 \text { * } \\
(0.001)\end{array}$ \\
\hline Female & $\begin{array}{l}-0.117^{* * *} \\
(0.013)\end{array}$ & $\begin{array}{l}-0.117^{* * *} \\
(0.013)\end{array}$ & $\begin{array}{l}-0.117^{* * *} \\
(0.013)\end{array}$ & $\begin{array}{l}0.009 \\
(0.027)\end{array}$ & $\begin{array}{l}0.009 \\
(0.027)\end{array}$ & $\begin{array}{l}0.009 \\
(0.027)\end{array}$ \\
\hline Black & $\begin{array}{l}-0.068^{* * *} \\
(0.021)\end{array}$ & $\begin{array}{l}-0.066^{* * *} \\
(0.021)\end{array}$ & $\begin{array}{l}-0.068^{* * *} \\
(0.021)\end{array}$ & $\begin{array}{l}0.022 \\
(0.045)\end{array}$ & $\begin{array}{l}0.032 \\
(0.045)\end{array}$ & $\begin{array}{l}0.021 \\
(0.045)\end{array}$ \\
\hline Latino & $\begin{array}{l}-0.062 \text { * } \\
(0.031)\end{array}$ & $\begin{array}{l}-0.059 \dagger \\
(0.031)\end{array}$ & $\begin{array}{l}-0.063 \text { * } \\
(0.031)\end{array}$ & $\begin{array}{l}-0.136 \text { * } \\
(0.067)\end{array}$ & $\begin{array}{l}-0.116 \dagger \\
(0.067)\end{array}$ & $\begin{array}{l}-0.136 \text { * } \\
(0.067)\end{array}$ \\
\hline Income & $\begin{array}{l}0.011 \dagger \\
(0.006)\end{array}$ & $\begin{array}{l}0.011 \dagger \\
(0.006)\end{array}$ & $\begin{array}{l}0.011 \dagger \\
(0.006)\end{array}$ & $\begin{array}{l}0.065^{* * *} \\
(0.013)\end{array}$ & $\begin{array}{l}0.625 \text { *** } \\
(0.013)\end{array}$ & $\begin{array}{l}0.065^{* * *} \\
(0.013)\end{array}$ \\
\hline $1984-1996$ & & $\begin{array}{l}0.045^{* *} \\
(0.015)\end{array}$ & $\begin{array}{l}0.009 \\
(0.021)\end{array}$ & & $\begin{array}{l}0.162^{* * *} \\
(0.031)\end{array}$ & $\begin{array}{l}0.015 \\
(0.040)\end{array}$ \\
\hline $1996-2004$ & & $\begin{array}{l}0.057^{* * *} \\
(0.016)\end{array}$ & $\begin{array}{l}0.015 \\
(0.023)\end{array}$ & & $\begin{array}{l}0.212^{* * *} \\
(0.031)\end{array}$ & $\begin{array}{l}0.010 \\
(0.829)\end{array}$ \\
\hline Constant & $\begin{array}{l}-0.016 \\
(0.042)\end{array}$ & $\begin{array}{l}0.064 \\
(0.039)\end{array}$ & $\begin{array}{l}-0.003 \\
(0.047)\end{array}$ & $\begin{array}{l}0.515^{* * *} \\
(0.092)\end{array}$ & $\begin{array}{l}0.830 * * * \\
(0.086)\end{array}$ & $\begin{array}{l}0.528^{* * *} \\
(0.100)\end{array}$ \\
\hline Adj. $R^{2}$ & 0.09 & 0.09 & 0.09 & 0.08 & 0.08 & 0.08 \\
\hline$N$ & 14,767 & 14,767 & 14,767 & 11,646 & 11,646 & 11,646 \\
\hline
\end{tabular}


Since the regression results reported in Table 1 analyze the effects of elite polarization on the electorate in aggregate (i.e., the average effects), we might think that citizens would respond differently to a polarized political environment depending on their existing political positions. For example, Fiorina et al. (2006, 2008) argue that ideological polarization has not extended from elites to the general electorate, or, alternately, that the polarization of individuals is confined to a small segment of the population (e.g., party activists). Therefore, assuming that party activists have more extremist political positions, I test if elite polarization has stronger effects on individuals at the extremes using quantile regression.

Figure 1. Effects of Growing Elite Polarization on Different Quantiles of Mass Ideological Positions
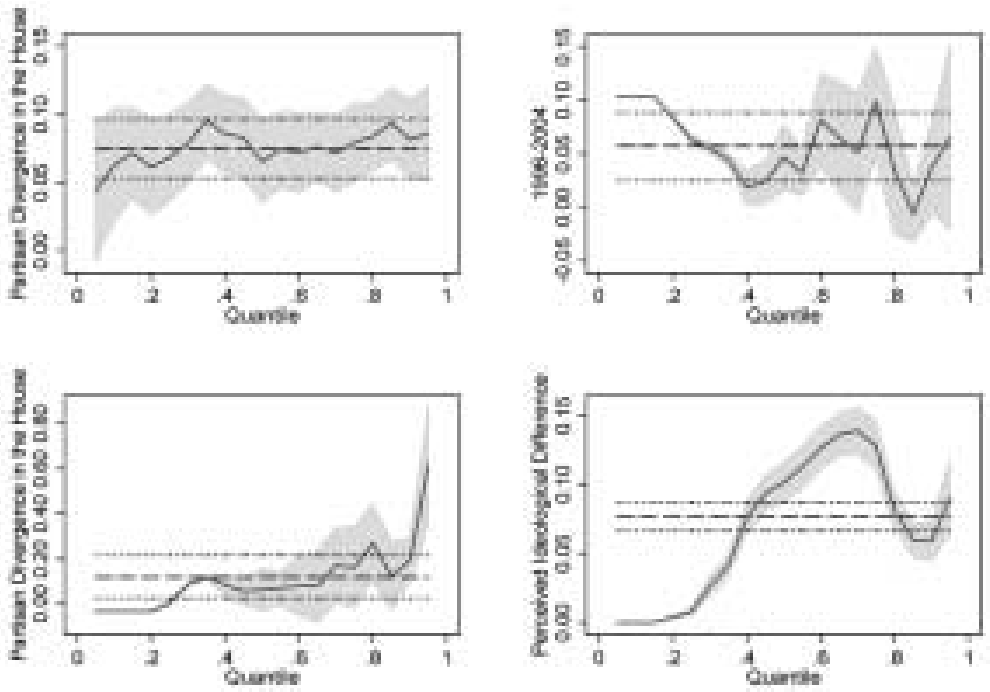

Note: Dotted horizontal lines represent estimated OLS coefficients for each model with 95 percent confidence intervals. Solid green lines plot the regression coefficients of covariates estimated in different quantiles of the dependent variable (ideological extremism). The grey bands enclosing the quantile regression lines indicate analytic (non-bootstrapped) 95 percent confidence intervals. The graphs are created by using thegrqreg function (Azevedo 2004) in STATA.

Figure 1 illustrates the results of the quantile regressions by displaying disproportionate effects of elite polarization on different quantiles of the ideological distribution of the masses. Each of the four panels in Figure 1 reports estimated OLS coefficients (dotted horizontal lines) and their 95 percent confidence intervals for the variable of interest and estimated quantile coefficients with their 95 percent confidence band. The first column of Figure 1 presents the quantile regression 
outputs for the ideological divergence variable estimated using models (1) and (3), respectively, while the first plot in the second column graphs the quantile coefficients of the period effects (1996-2004) in model (2). Finally, the last panel represents the quantile effects of the perceived ideological distance on the ideological distribution of the masses. Provided that perceived ideological distance tends to increase with growing elite polarization, the perceived difference could be used as an indirect measure of elite polarization (Hetherington 2001). Therefore, I add the variable into the estimation model (3) and then investigate the differential effects of perceived distance on each quantile of the ideological deviation measure.

As shown in Figure 1, the included variables marked on each vertical axe tend to have consistent effects across different quantiles of the dependent variable (ideological deviation) in the four panels. The graph in the first row of Figure 1 reveals that the effects of congressional divergence do not deviate significantly from the average effect (OLS estimate) and is bound between the 95 percent confidence intervals of the OLS coefficient. The effects of a period dummy (19962004) shift the OLS estimatesup or down, but these shifts do not indicate the presence of pronounced effects on the higher quantiles of the dependent variable. The evidence of the stronger effects of divergence on ideological extremists is shown to some degree in the first graph of the second column, but the effects in the rest of the quantiles (almost up until the 90 percentiles) consistently stay around the mean effect except for those at the extreme end. Furthermore, the last plot indicates that the ideological effect is strongest among people located at moderately extreme positions rather than with the extremistsif disproportionate effects exist. Indeed, the quantile graph of the perceived differences display a concave shape indicating that the effects tend to be lower than the average effect (OLS estimate) for respondents who are ideological moderate, are higher than the average for those who are moderately extremists, and are about the average effect for extremists. To summarize the findings in this section, as congressional members become more divergent, individuals are more likely to take more extreme positions. Moreover, the positive effects of elite polarization on individual ideological deviation tend to be consistent rather than being disproportionate across the existing ideological positions of those individuals.

\section{THE EFFECTS OF GROWING ELITE POLARIZATION ON MASS POLITICAL AWARENESS}

The findings above indicate that the mass public became ideologically more 
aware and more polarized with increasing elite polarization. Then, what about the levels of mass political awareness? Similar to the mass polarization model above, I estimated the effects of elite polarization on political awareness using two contextual measures (divergence and period effects) of elite polarization. As I estimated the empirical model for political awareness, I tested the two different models with and without political interest and media exposure variables given that these two potentially endogenous variables sometimes could be used to measure political awareness when enough items were not available (Zaller 1992).

Table 2. The Effects of Elite Polarization on Mass Political Awareness

\begin{tabular}{|c|c|c|c|c|c|c|}
\hline \multirow{2}{*}{ Variables } & \multicolumn{6}{|c|}{ Political Awareness } \\
\hline & (7) & (8) & (9) & (10) & (11) & (12) \\
\hline $\begin{array}{l}\text { Divergence } \\
\text { in the House }\end{array}$ & $\begin{array}{l}0.075^{* * *} \\
(0.011)\end{array}$ & $\begin{array}{l}0.220 * * * \\
(0.012)\end{array}$ & $\begin{array}{l}0.017 \\
(0.017)\end{array}$ & & & $\begin{array}{l}0.145^{* * *} \\
(0.019)\end{array}$ \\
\hline Strong Partisanship & $\begin{array}{l}0.065 * * * \\
(0.003)\end{array}$ & $\begin{array}{l}0.049 * * * \\
(0.003)\end{array}$ & $\begin{array}{l}0.065 \text { *** } \\
(0.003)\end{array}$ & $\begin{array}{l}0.064 \text { *** } \\
(0.003)\end{array}$ & $\begin{array}{l}0.048^{* * *} \\
(0.003)\end{array}$ & $\begin{array}{l}0.048^{* * *} \\
(0.003)\end{array}$ \\
\hline Interest in Politics & & $\begin{array}{l}0.079 * * * \\
(0.003)\end{array}$ & & & $\begin{array}{l}0.082 \text { *** } \\
(0.003)\end{array}$ & $\begin{array}{l}0.080^{* * *} \\
(0.003)\end{array}$ \\
\hline Media Exposure & & $\begin{array}{l}0.059 * * * \\
(0.003)\end{array}$ & & & $\begin{array}{l}0.056 \text { *** } \\
(0.003)\end{array}$ & $\begin{array}{l}0.059 * * * \\
(0.003)\end{array}$ \\
\hline Political Efficacy & $\begin{array}{l}0.022 * * * \\
(0.002)\end{array}$ & $\begin{array}{l}0.014^{* * *} \\
(0.002)\end{array}$ & $\begin{array}{l}0.022 \text { *** } \\
(0.002)\end{array}$ & $\begin{array}{l}0.023 \text { *** } \\
(0.002)\end{array}$ & $\begin{array}{l}0.013 \text { *** } \\
(0.002)\end{array}$ & $\begin{array}{l}0.014^{* * *} \\
(0.002)\end{array}$ \\
\hline Education & $\begin{array}{l}0.150 * * * \\
(0.003)\end{array}$ & $\begin{array}{l}0.109 * * * \\
(0.003)\end{array}$ & $\begin{array}{l}0.151 \text { *** } \\
(0.003)\end{array}$ & $\begin{array}{l}0.146 \text { *** } \\
(0.003)\end{array}$ & $\begin{array}{l}0.106 \text { *** } \\
(0.003)\end{array}$ & $\begin{array}{l}0.108^{* * *} \\
(0.004)\end{array}$ \\
\hline Age & $\begin{array}{l}0.002 * * * \\
(0.0002)\end{array}$ & $\begin{array}{l}0.001^{* * *} \\
(0.0002)\end{array}$ & $\begin{array}{l}0.002 \text { *** } \\
(0.0002)\end{array}$ & $\begin{array}{l}0.002 * * * \\
(0.0001)\end{array}$ & $\begin{array}{l}0.001 \text { *** } \\
(0.0002)\end{array}$ & $\begin{array}{l}0.001^{* * *} \\
(0.0002)\end{array}$ \\
\hline Female & $\begin{array}{l}-0.094^{* * *} \\
(0.005)\end{array}$ & $\begin{array}{l}-0.053^{* * *} \\
(0.005)\end{array}$ & $\begin{array}{l}-0.094 * * * \\
(0.005)\end{array}$ & $\begin{array}{l}-0.091 \text { *** } \\
(0.005)\end{array}$ & $\begin{array}{l}-0.051 \text { *** } \\
(0.005)\end{array}$ & $\begin{array}{l}-0.052 \text { *** } \\
(0.005)\end{array}$ \\
\hline Black & $\begin{array}{l}-0.075^{* * *} \\
(0.008)\end{array}$ & $\begin{array}{l}-0.073^{* * *} \\
(0.009)\end{array}$ & $\begin{array}{l}-0.076 \text { *** } \\
(0.008)\end{array}$ & $\begin{array}{l}-0.076^{* * *} \\
(0.008)\end{array}$ & $\begin{array}{l}-0.071 \text { *** } \\
(0.008)\end{array}$ & $\begin{array}{l}-0.072 \text { *** } \\
(0.009)\end{array}$ \\
\hline Latino & $\begin{array}{l}-0.054 \text { *** } \\
(0.012)\end{array}$ & $\begin{array}{l}-0.060^{* * *} \\
(0.013)\end{array}$ & $\begin{array}{l}-0.056 \text { *** } \\
(0.012)\end{array}$ & $\begin{array}{l}-0.058^{* * *} \\
(0.012)\end{array}$ & $\begin{array}{l}-0.060 * * * \\
(0.013)\end{array}$ & $\begin{array}{l}-0.062 \text { *** } \\
(0.013)\end{array}$ \\
\hline Income & $\begin{array}{l}0.040 * * * \\
(0.003)\end{array}$ & $\begin{array}{l}0.028^{* * *} \\
(0.003)\end{array}$ & $\begin{array}{l}0.040 \text { *** } \\
(0.003)\end{array}$ & $\begin{array}{l}0.040 * * * \\
(0.002)\end{array}$ & $\begin{array}{l}0.027^{* * *} \\
(0.003)\end{array}$ & $\begin{array}{l}0.028^{* * *} \\
(0.003)\end{array}$ \\
\hline 1984-1996 & & & $\begin{array}{l}0.034 \text { *** } \\
(0.007)\end{array}$ & $\begin{array}{l}0.035^{* * *} \\
(0.005)\end{array}$ & $\begin{array}{l}0.066 * * * \\
(0.005)\end{array}$ & $\begin{array}{l}0.037^{* * *} \\
(0.007)\end{array}$ \\
\hline 1996-2004 & & & $\begin{array}{l}0.027^{* * *} \\
(0.009)\end{array}$ & $\begin{array}{l}0.033^{* * *} \\
(0.006)\end{array}$ & $\begin{array}{l}0.082 \text { *** } \\
(0.007)\end{array}$ & $\begin{array}{l}0.033^{* * *} \\
(0.009)\end{array}$ \\
\hline Constant & $\begin{array}{l}0.314 \text { *** } \\
(0.015)\end{array}$ & $\begin{array}{l}0.129 * * * \\
(0.017)\end{array}$ & $\begin{array}{l}0.334^{* * *} \\
(0.017)\end{array}$ & $\begin{array}{l}0.358^{* * *} \\
(0.014)\end{array}$ & $\begin{array}{l}0.249 * * * \\
(0.015)\end{array}$ & $\begin{array}{l}0.158^{* * *} \\
(0.018)\end{array}$ \\
\hline Adj. $R^{2}$ & 0.34 & 0.45 & 0.35 & 0.34 & 0.44 & 0.45 \\
\hline$N$ & 13,001 & 9,710 & 13,001 & 14,250 & 10,965 & 9,710 \\
\hline
\end{tabular}


Table 2 summarizes the regression outputs for predictions for political awareness. As expected, the results indicate that an increasing ideological divergence among elites significantly enhances levels of political awareness among citizens. It turns out that the level of public political awareness among the general electorate increaseson average with a growing ideological divergence in the House (see the positive coefficients for the divergence variable in models 7,8 , and 12). Together with the divergence variable, the period effects for 1984-1996 and 19962004 also reveal that public political awareness increases with time (see models $9,10,11$ and 12). However, the positive effects of period dummies could be an artifact of the natural increase of political awareness with time instead of the influence of growing elite polarization, so I include both the divergence variable and period dummies in the same empirical model to partial out the pure time effects (models 9 and 12). As we control for time, the divergence variable in model 7 becomes insignificant in model 9. This might indicate that mass political awareness increased not because of growing elite polarization but because of pure time effects. Except for model 9, however, the positive significant effects of ideological divergence are consistently shown across different model specifications in the table. In particular, in the full model 12, which incorporates political interest and media exposure to the estimation as controls, the positive significant sign remains on the divergence variable even after we account for the period effects. Thus, the exclusion of political interest and media exposure variables yields significantly different estimation results only between models 9 and 12 .

The findings here suggest that growing ideological divergence in the House tends to enhance mass political awareness when we control for time and other relevant factors including levels of political interest and media exposure. Indeed, both measures of elite polarization (congressional divergence and the period effects) are positively associated with levels of mass political awareness. If the electorate became more politically aware as its representatives diverged, what about the role of existing levels of political sophisticationvarying over individual attitudes? Do individuals respond differently to the changing informational environment according to their existing levels of knowledge? Applying quantile regression to the empirical model 12, I test for the unequal effects of elite polarization on different quantiles of the dependent variable (political awareness). 
Figure 2. Effects of Growing Elite Polarization on Different Quantiles of Mass Political Awareness
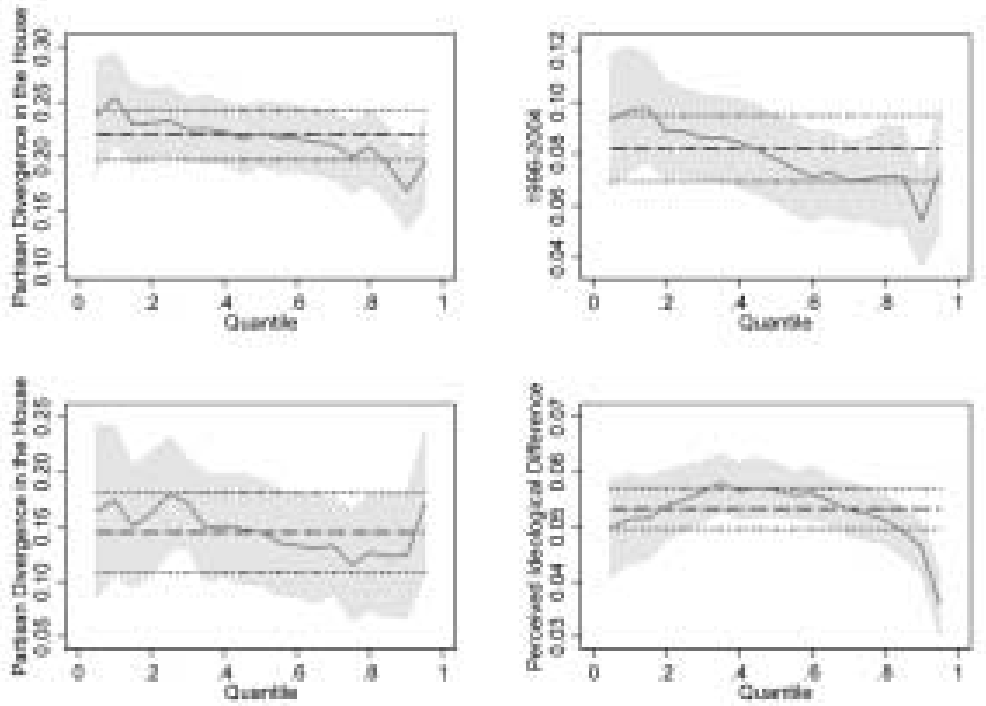

Note: Dotted horizontal lines represent estimated OLS coefficients for each model with 95 percent confidence intervals. Solid green lines plot regression coefficients of covariates estimated in different quantiles of the dependent variable (political awareness) The grey bands enclosing the quantile regression lines indicate analytic (non-bootstrapped) 95 percent confidence intervals. The graphs are created by using grqregfunction (Azevedo 2004) in STATA.

Figure 2 illustrates the results of quantile regressions by displaying the disproportionate effects of elite polarization on different quantiles of mass political awareness. Each panel in Figure 2 reports estimated OLS coefficients (dotted horizontal lines) and their 95 percent confidence intervals for the variable of interest and estimated quantile coefficients with their 95 percent confidence band. The first column of Figure 2 presents the quantile regression outputs for the ideological divergence variable estimated using models (8) and (12), respectively, to examine how the conditional quantile effects of divergence change depending on the inclusion of the period effects in the same model. The first plot in the second column graphs the quantile coefficients of the period effects (1996-2004) in model (11) that only includes those time effects as proxies for elite polarization. Finally, the last panel reports the quantile effects of perceived ideological distance on mass political awareness after adding the perceived distance variable as an indirect measure of elite polarization into the full model (model 12).

The graphical outputs of quantile regressions presented in Figure 2 indicate that the effects of various measures of elite polarization are consistent with mass 
political awareness across different quantiles of the dependent variable. Solid green lines representing conditional quantile effects do not deviate significantly away from average effects (dotted horizontal lines) in the three panels, except for the last panel that addressesthe perceived distance variable. The fitted lines of quantiles regressions are bounded by the 95 percent confidence intervals of OLS estimates in the panels of the divergence variable and the time effect for 19962004. Moreover, although the quantile regression lines shift the OLS horizontal linesup or down, the results do not support the presence of stronger effects on the higher quantiles. Finally, the last panel of Figure 2 demonstrates that the group of respondents with the highest level of awareness could be least advantaged in terms of becoming more aware by growing elite polarization. The curve for the quantile effects of the perceived distance exhibits an inverse-U shape similar to the variable's effects in the ideological extremism model above. To summarize, the findings imply that a majority of citizens became politically more aware due to growing elite polarization (see positive horizontal lines in each panel). Growing elite polarization has consistent effects on mass political awareness ranging from the least politically aware group to the most aware group rather than disproportionately advantaging the latter.

\section{CONCLUSION AND IMPLICATIONS}

The findings here suggest that the general electorate not only comes to perceive more ideological differences between the two parties, but members also tend to adopt more extreme positions on an ideological self-placement scale as congressional members become more polarized.In addition, the effects of growing ideological divergence among elites are consistent with the polarization of the masses rather than being disproportionate across different ideological positions of citizens. Indeed, as I compare the sign and magnitude of the conditional effects on different quantiles of the dependent variable (ideological extremism), I found that a similar degree of positive effects present across different levels of existing ideological orientations (e.g., moderate, moderate ideological, more ideological, and extremist) rather than being confined to the more ideological-driven groups.This result contrasts sharply with the claim of Fiorina et al. (2006), who argued that mass polarization was largely confined to political activists with a stronger ideological orientation.

When it comes to mass political awareness, the growing ideological divergence between the parties tends to enhance the public's political awareness in aggregate. Furthermore, both measures of elite polarization indicate that a significant 
relationship is consistent across all levels of political awareness rather than disproportionately advantaging the most politically aware groups. Indeed, enhancing effects are found among the politically less aware groups as well as those that are more aware. This finding was in contrast to the findings of Claassen and Highton (2009) who demonstrated that only the well-informed strata of the population responded to growing elite polarization.

Taken together, the empirical evidence presented in this study indicates that a more polarized political environment of elites brought about significant changes in mass political attitudes and behavior. In addition to the overall shift in mass ideological distribution, ordinary citizens responded to the changing political environment by taking more extreme positions. Furthermore, rather than the transformation brought about by increasing elite polarization being confined to a small subset of the population with greater political knowledge, ordinary citizens with less knowledge also became politically more aware while becoming more interested in election outcomes in response to changes in elite attitudes and behavior. The findings presented here suggest that growing political polarization is not necessarily bad for democratic citizenship in American politics. The growing ideological divergence of legislative members can help informed the decisions of voters by presenting more clearly differentiated policy positions, thus improving the quality of democratic decisions accordingly. Despite these optimistic prospects about growing ideological polarization, we are still uncertain as to whether the knowledge gap between the most informed and the least informed groups was reduced as elite attitudes became more polarized.Thus, future research should focus on how the positive informational effects resulting from growing elite polarization transform existing knowledge gaps among different citizen groups.

\section{REFERENCES}

Abramowitz, A. A. 2006. "Disconnected or Joined at the Hip? Comments on Chapter Two." In P. S. Nivola and D. W. Brady. eds. Red and Blue Nation? Characteristics and Causes of America's Polarized Politics, Washington, D. C.: Brookings Institution Press. . 2011. The Disappearing Center: Engaged Citizens, Polarization, and American Democracy. New Haven, CT.: Yale University Press.

Abramowtiz, A. A. and K. L. Saunders. 1998. "Ideological Realignment in the U.S. Electorate." Journal of Politics 60(3), 634-652. . 2008. "Is Polarization a Myth?" The Journal of Politics 70(2), 542-555. 
Baldassarri, D. and A. Gelman. 2008. "Partisans Without Constraint: Political Polarization and Trends in American Public Opinion." American Journal of Sociology 114(2), 484-546.

Barabas, J. 2002. "Another Look at the Measurement of Political Knowledge." Political Analysis 10(2), 1-14.

Bimber, B. 2001. "Information and Political Engagement in America: The Search for Effects of Information Technology at the Individual Level." Political Research Quarterly 54(1), 53-67.

Brewer, M. 2005. "The Rise of Partisanship and the Expansion of Partisan Conflict Within the American Electorate." Political Research Quarterly 58(2), 219-229.

Brooks D. J. and J. Geer. 2008. "Comments on Chapter One." In P. S. Nivola and D. W. Brady. eds. Red and Blue Nation? Consequences and Correction of America's Polarized Politics, Washington, D. C.: Brookings Institution Press.

Carmines E. and J. Stimson. 1989. Issue Evolution: Race and the Transformation of American Politics. Princeton, N.J.: Princeton University Press.

Claassen, B. and B. Highton. 2009. "Policy Polarization Among Party Elites and the Significance of Political Awareness in the Mass Public." Political Research Quarterly 62(3), 538-551.

Converse, P. 1964. "The Nature of Belief Systems in Mass Publics.” In D. Apter. ed. Ideology and Discontent, New York: Free Press.

DelliCarpini, M. and S. Keeter. 1993. "Measuring Political Knowledge: Putting First Things First." American Journal of Political Science 37(4), 11791206.

Dow, J. K. 2009. "Gender Differences in Political Knowledge: Distinguishing Characteristics-based and Return-based Differences." Political Behavior 31, 117-136.

Downs, A. 1957. An Economic Theory of Democracy. New York: Harper and Row. Ellis, C. and J. Ura. 2008. "United We Divide? Education, Income, Heterogeneity in Mass Partisan Polarization." Paper presented at annual meeting of the American Political Science Association.

Fiorina, M. P., S. Abrams and J. C. Pope. 2006. Culture War? The Myth of a Polarized America. New York: Pearson Longman. . 2008. "Polarization in the American Public: Misconceptions and Misreadings." Journal of Politics 70, 556-560.

Fiorina, M. P., and S. Abrams. 2008. "Political Polarization in the American Public." Annual Review of Political Science 11, 563-588. . 2009. Disconnect: The Breakdown of Representation in American 
Politics. Norman: University of Oklahoma Press.

Fiorina, M. P., and M. Levendusky. 2006. "Disconnected: The Political Class Versus the People.” In P. S. Nivola and D. W. Brady. eds. Red and Blue Nation? Characteristics and Causes of America's Polarized Politics, Washington, D. C.: Brookings Institution Press.

Gelman, A. 2008. Red State, Blue State, Rich State, Poor State: Why Americans Vote the Way They Do. Princeton, NJ: Princeton University Press.

Hao, L. and D. Q. Naiman. 2007. Quantile Regression. Thousand Oaks, CA: Sage Publications.

Hetherington, M. 2001. "Resurgent Mass Partisanship: The Role of Elite Polarization." American Political Science Review 95(3), 619-631. . 2008. "Turned Off or Turned On? How Polarization Affects Political Environment." In P. S. Nivola and D. W. Brady. eds. Red and Blue Nation? Consequences and Correction of America's Polarized Politics, Washington, D. C.: Brookings Institution Press. . 2009. "Putting Polarization in Perspective." British Journal of Political Science 39, 413-448.

Holbrook, T. M. 2002. "Presidential Campaigns and the Knowledge Gap." Political Communication 19, 437-454.

Hussey, L. 2012. "Polarized Politics and Citizen Disengagement: The Role of Belief Systems." American Politics Research 20(10), 1-31.

Jacobson, G. C. 2006. “Comments on Chapter Two.” In P. S. Nivola and D. W. Brady. eds. Red and Blue Nation? Characteristics and Causes of America's Polarized Politics, Washington, D.C.: Brookings Institution Press.

. 2011. A Divider, Not a Uniter: George W. Bush and the American People, The 2006 Election and Beyond. London: Longman Publisher.

Koenker, R. and K. Hallock. 2001. "Quantile Regression." Journal of Economic Perspectives 15(4), 143-156.

Larcinese, V. 2007. "Does Political Knowledge Increase Turnout? Evidence from the 1997 British General Election." Public Choice 131, 387-411.

Lassen, D. 2005. "The Effect of Information on Voter Turnout: Evidence from a Natural Experiment.” American Journal of Political Science 49(1), 103118.

Layman, G. C., T. M. Carsey, and J. M. Horowitz. 2006. "Party Polarization in American Politics: Characteristics, Causes, and Consequences.” Annual Review of Political Science 9, 83-110.

Levendusky, M. S. 2009. The Partisan Sort. Chicago: University of Chicago Press. . 2010. "Clearer Cues, More Consistent Voters: A Benefit of Elite 
Polarization." Political Behavior 32(1), 111-131.

Matsusaka, J. 1995. "Explaining Voter Turnout: An Informational Theory." Public Choice 84, 91-117.

Mayhew, D. 1974. Congress: the Electoral Connection. New Haven, CT.: Yale University Press.

McCarty, N., K.T. Poole, and H. Rosenthal. 2006. Polarized America: The Dance of Ideology and Unequal Riches. Cambridge, M.A.: MIT Press.

Mondak, J. 1999. "Reconsidering the Measurement of Political Knowledge." Political Analysis 8(1), 57-82.

Riker, W. and P. Ordeshook. 1968. "A Theory of the Calculus of Voting." American Political Science Review 62(1), 25-42.

Rogowski, J. 2012. "Electoral Choice, Ideological Conflict, and Political Participation." Unpublished manuscript.

Theriault, S. 2008. Party Polarization in Congress. New York: Cambridge University Press.

Tolbert, C., R. McNeal, and D. Smith. 2003. "Enhancing Civic Engagement: The Effect of Direct Democracy on Political Participation and Knowledge." State Politics and Policy Quarterly 3(1), 23-41.

Zaller, J. 1992. The Nature and Origin of Public Opinion. Cambridge: Cambridge University Press. 
APPENDIX: MEASUREMENT OF POLITICAL AWARNESS

This appendix introduces a list of ANES items used to measure political awareness, along with specific coding rules for those respective indicators.

- Interviewer rating (VCFoo50a):The respondent's general level of political knowledge evaluated by ANSE interviewers. I coded o (fairly low and very low), coded 1 (average), and coded 2 (fairly high and very high).

- Correct relative placement of political objects (parties and presidential candidates) on policy and ideological issue dimensions: I coded 2 if respondents locate the Democratic Party (or presidential candidate) to the left of the Republican Party (or presidential candidate) on a 7-point ideological scale. I coded 1 if respondents placed the two political objects in the same position. I coded o if respondent located Republicans to the left of the Democrats. Issue items include government guarantees (VCF9087 and VCF9095), minority (black) policies (VCF9084 and VCF9092), and general liberal-conservative ideological scales for the two parties (VCFO503 and VCF0504) and for presidential candidates (VCF9o88 and VCF9096).

- Willingness to ratepolitical objects on feelings thermometers: I coded o if respondent did not give a thermometer rating, coded 1 if they gave a rating of 50 , and coded 2 if they gave a non-50 rating. The feelings thermometers used concerned both Democratic and Republican presidential candidates (VCFo424 and VCFo426) and both presidents and vice presidents (VCFo428 and VCF0429).

- Attitudes toward major political parties or presidential candidates (likes ordislikes felt towards major parties or party leaders): I coded o if respondents provided no reasons to like (dislike) the party, coded 1 if they provided one reason, and coded 2 if they provided more than one reason (2-5). Specific ANES items measuring party salience addressed attitudes towards the Democratic Party (VCFo314 and VCFo315), the Republican Party (VCFo318 and VCFo319), Democratic presidential candidates (VCFO4O1 and VCFo402) and Republican presidential candidates (VCFo405 and VCF0406).

- Two indicators for factual political knowledge: Knew which was the majority party in the House (o or 1, VCFo729), and knew the incumbency status of House candidates (o or 1, VCFo978, not included in 2004 survey). Incorrect answers (o) were included along with “don't know” answers. 